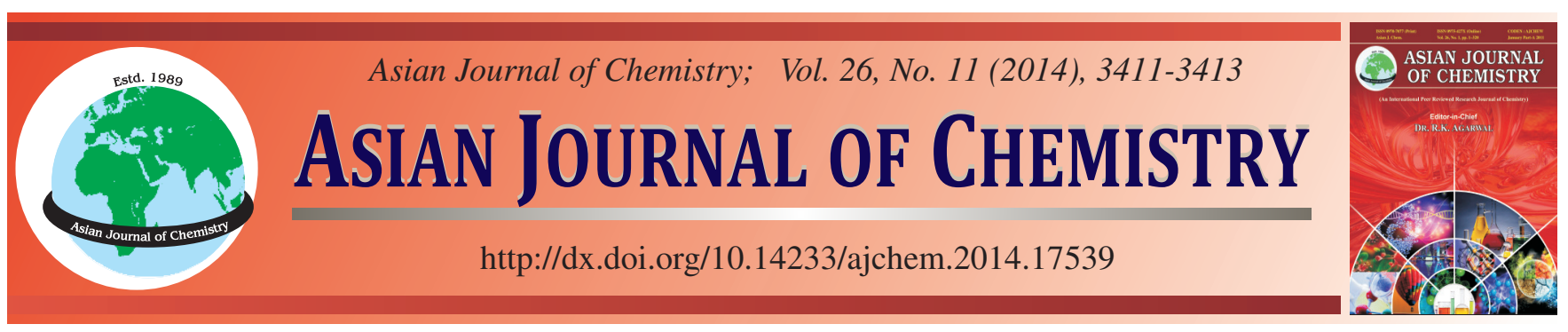

\title{
Laboratory Research of Using Activated Carbon to Dispose the Wastewater Containing Lead
}

\author{
Xu LuO* and GuANGJUN YANG
}

Zhengzhou Institute of Aeronautical Industry Management, Henan 450015, P.R. China

*Corresponding author: E-mail: snower@zzia.edu.cn

\begin{abstract}
Wastewater containing lead is dangerous to the health of human being and plants and animals. In recent years, people use different methods to deal with wastewater containing lead, such as activated carbon absorption material to take in lead ions. This study introduces the absorption action and mechanism of activated carbon to absorb lead ion in wastewater. And discussing the influence of adsorption effect when some factors are different, e.g., the different adsorbent dosage, stir time, $\mathrm{pH}$, concentration of wastewater and adsorbent regeneration etc. Experimental results show that when the activated carbon dosage is $20 \mathrm{~g} / \mathrm{L}$ stirring at room temperature ( $110 \mathrm{rpm})$ for 0.5 $\mathrm{h}, \mathrm{pH}$ 6-7, after processing, the removal rate of lead ion in wastewater is up to the best, the residual concentration is $0.08 \mathrm{mg} / \mathrm{L}$, below the standard of national comprehensive discharge standard (GB25466-2010).
\end{abstract}

Keywords: Dosage of activated carbon, Adsorption, Wastewater containing lead, Absorbancy.

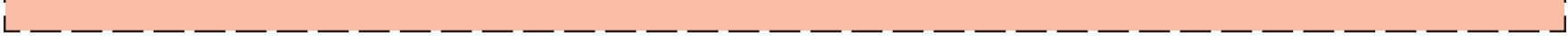

\section{INTRODUCTION}

Wastewater containing lead mainly comes from the industries which include petroleum chemical plant, battery workshops, beneficiation factories, lead-acid battery recycling industries ${ }^{1}$. Amongst these industries, the battery industry is the main source of wastewater containing lead. Lead is a great harm to human health and ecological environment. It is reported that if the intake is more than $0.3-1.0 \mathrm{mg}$, it could cause diseases of hematopoietic system, nervous system and digestive system. State requirements for discharge of wastewater containing lead must be less than highest of pollutant emission standard of the first kind of pollutant. However, some industries, especially in battery industry the quantity of containing lead in wastewater is usually several times higher than the national standard, is a great harm to water resources, therefore, to deal with wastewater containing lead is always an important hot topic.

At present, the treatment technologies of wastewater containing lead are: ion exchange method, precipitation method, adsorption method, electrolytic process and the combination of the above process. Chemical precipitation is a popular and good method currently, but in the end, the lead salt sediment is hard to handle, easily cause secondary pollution. Ion exchange is the method which using ion exchanger to separate harmful substances in wastewater ${ }^{2}$. Biosorption is the method which use the natural affinity with heavy metals of biological materials to purify the lead ions and mixed metal ions in wastewater. Physical adsorption is the method which using the special physical and chemical properties of adsorbent for adsorption of heavy metals. Electrolytic process is the way which the heavy metal ions are restored to metal through getting electron in the cathode surface ${ }^{3}$.

As the first kind of pollutant, lead harm to the environment and resources seriously, therefore, in the national emission standard, the emission standard of wastewater containing lead is specified as total content of lead is $1 \mathrm{mg} / \mathrm{L}^{4}$. And the lead themselves can not degrade naturally, only through all kinds of artificial way to reduce the concentration of the wastewater containing lead. As a kind of non-polar adsorbent, the sources of active carbon is abundant, is one of the most widely using adsorbent in wastewater treatment. It has a good adsorption performance and stable chemical properties, can resistant to strong acid, strong alkali, can withstand water, high temperature and high pressure, at the same time can also activate regeneration. This experiment deals with containing lead wastewater treatment using activated carbon as adsorbent, it can get best adsorption processing conditions through the experiment way, providing a reference for practice. 


\section{EXPERIMENTAL}

Lead nitrate, sodium nitrate, volumetric flask, alcohol lamp, activated carbon, beaker, $722 \mathrm{~g}$ visible spectrophotometer, electronic scales, oscillators, 1, 2, 5, 10, 15, 20, 50 and $100 \mathrm{~mL}$ pipette are required for present work.

\section{Experimental method}

Drawing lead standard curve: Compounding concentration of $30 \mathrm{mg} / \mathrm{L}$ of lead standard using solution, take 1.0, 2.0, 5.0, 10.0, 15.0 and $20.0 \mathrm{~mL}$ lead standard using solution in turn in $100 \mathrm{~mL}$ volumetric flask and adding nitric acid of $0.2 \%$ to constant volumn. With sodium nitrate as the chromogenic agent, after chromogenic reaction operating, under the absorption wavelength of $283.3 \mathrm{~nm}$, using $722 \mathrm{G}$ visible spectrophotometer to measure the absorbance of $\mathrm{Pb}^{2+}$. Put the concentration of lead as the abscissa and corresponding absorbance as the ordinate, drawing standard curve in the following Table-1 and Fig. 1.

\begin{tabular}{cccccccc}
\multicolumn{8}{c}{ TABLE-1 } \\
LEAD CONCENTRATIONS AND THE \\
CORRESPONDING ABSORBANCE \\
\hline $\begin{array}{c}\text { Conc. of } \\
\text { lead (mg/L) }\end{array}$ & 0 & 0.3 & 0.6 & 1.5 & 3.0 & 4.5 & 6.0 \\
\hline Absorbance & 0 & 0.008 & 0.016 & 0.04 & 0.084 & 0.132 & 0.178 \\
\hline
\end{tabular}

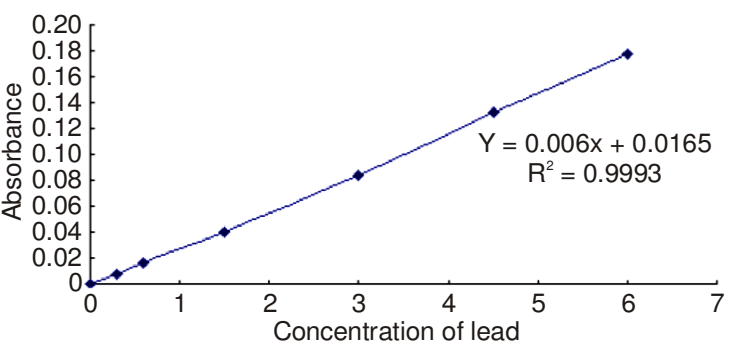

Fig. 1. Lead standard curve

\section{RESULTS AND DISCUSSION}

Amount of activated carbon effect on the treatment effect: Taking $100 \mathrm{~mL}$ water in five of the $250 \mathrm{~mL}$ beaker, respectively, adding mass concentration of 5, 10, 15, 20, $25 \mathrm{~g} / \mathrm{L}$ of activated carbon in turn, stirring them under the speed of $110 \mathrm{rpm} 0.5 \mathrm{~h}$, analyzing supernatant, the results are shown in Table-2 and Fig. 2.

\begin{tabular}{|c|c|c|c|c|c|}
\hline $\begin{array}{r}\mathrm{T} \\
\text { EFFECT OF AC } \\
\text { CONCENTRATION T }\end{array}$ & $\begin{array}{l}\text { LE-2 } \\
\text { VATH } \\
\text { EAD }\end{array}$ & $\begin{array}{l}\text { CAR } \\
\mathrm{ON} \mathrm{AF}\end{array}$ & $\begin{array}{l}\text { ON } \\
\text { ORI }\end{array}$ & $\mathrm{ON}$ & \\
\hline Activated carbon conc. (g/L) & 5 & 10 & 15 & 20 & 25 \\
\hline $\begin{array}{l}\text { Activated carbon absorption } \\
\text { efficiency of lead ions }(\%)\end{array}$ & 94.9 & 95.5 & 96 & 99 & 98.1 \\
\hline
\end{tabular}

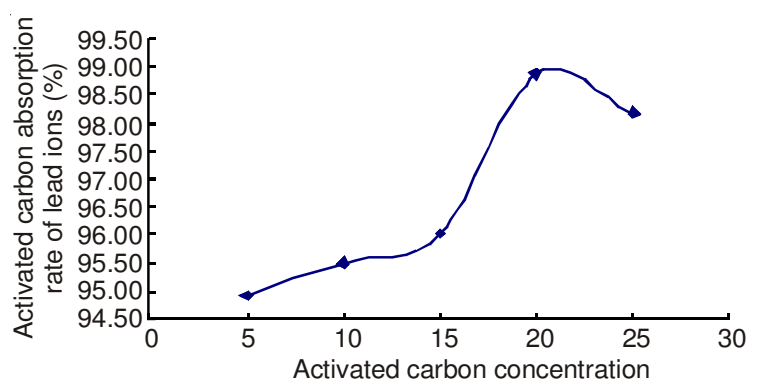

Fig. 2. Influence of amount of activated carbon on the treatment effect
The experimental results shows that with the increase of the amount of activated carbon, the removal rate of $\mathrm{Pb}^{2+}$ in waste water increases gradually, up to $99 \%$, continue to increase the amount of activated carbon, the removal rate invariable. When adsorbent dosage is greater than $2.0 \mathrm{~g}$, the removal rate is slightly lower, considering the limited adsorption capacity of activated carbon and the removal rate in comprehensive consideration, take the amount of activated carbon for $20 \mathrm{~g} / \mathrm{L}$.

Influence of mixing time on treatment effect: Taking $100 \mathrm{~mL}$ water in five of the $250 \mathrm{~mL}$ beaker, respectively, all of them adding the mass concentration of $20 \mathrm{~g} / \mathrm{L}$ of activated carbon, under the speed of $110 \mathrm{rpm}$, stirring them 10, 20, 30, 40 and $50 \mathrm{~min}$, respectively, analyzing supernatant, the results are shown in Table-3 and Fig. 3.

\begin{tabular}{|c|c|c|c|c|c|}
\hline $\begin{array}{l}\text { INFLUENCE } \\
\text { LEAD ION A }\end{array}$ & $\begin{array}{l}\text { ABLE- } \\
\text { F MIX } \\
\text { SORP }\end{array}$ & $\begin{array}{l}\text { NG TII } \\
\text { ON EI }\end{array}$ & $\begin{array}{l}\text { E TO } \\
\text { ECT }\end{array}$ & & \\
\hline Mixing time (min) & 10 & 20 & 30 & 40 & 50 \\
\hline Removal rate of lead ions (\%) & 93.5 & 96.0 & 98.5 & 97.9 & 97.0 \\
\hline
\end{tabular}

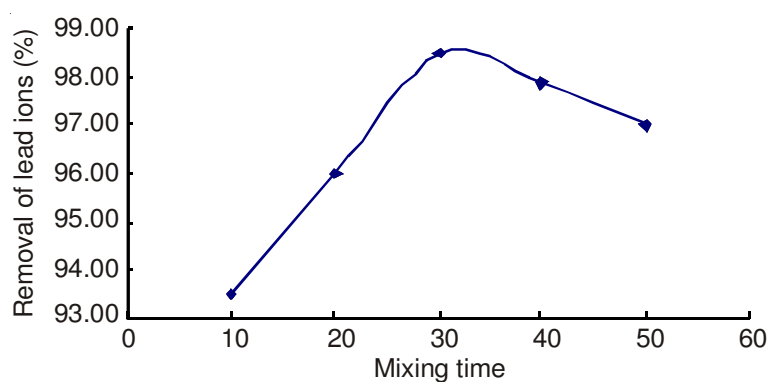

Fig. 3. Influence of mixing time to lead ion removal rate

The experimental results shows that the removal rate of $\mathrm{Pb}^{2+}$ augment with the increase of adsorption time, when the adsorption time is $0.5 \mathrm{~h}$, reached the highest removal rate, more than $0.5 \mathrm{~h}$, adsorption effect slightly down, subsequent test of processing time for $0.5 \mathrm{~h}$.

Influence of $\mathbf{p H}$ on the treatment effect: Taking 100 $\mathrm{mL}$ water in five of the $250 \mathrm{~mL}$ beaker, respectively, adjusting $\mathrm{pH}$ value of wastewater to 5, 6, 7, 8, 9 in order and then adding the mass concentration of $20 \mathrm{~g} / \mathrm{L}$ of activated carbon, stirring $0.5 \mathrm{~h}$, analyzing supernatant, the results in Table- 4 and Fig. 4.

TABLE-4

INFLUENCE OF pH ON THE TREATMENT EFFECT

\begin{tabular}{cccccc}
\hline $\mathrm{pH}$ & 5 & 6 & 7 & 8 & 9 \\
\hline Removal rate (\%) & 68.2 & 94.8 & 97.6 & 92.3 & 89.6 \\
\hline
\end{tabular}

By the experimental results, it can be seen that the removal rate of $\mathrm{Pb}^{2+}$ augment with the increase of $\mathrm{pH}$, around $\mathrm{pH}$ of 7 , maximum removal rate is $97.6 \%$, continue to increase $\mathrm{pH}$, the removal rate fell slightly. With the increase of solution $\mathrm{pH}$, the $\mathrm{H}^{+}$of solution combined with functional groups on the surface of the activated carbon will be dissociation, making a lot of active center exposed, $\mathrm{Pb}^{2+}$ are absorbed by occupy the active center, so the removal rate augments with the increase of $\mathrm{pH}$. With $\mathrm{pH}$ increase continuously, the chemical reaction enhance between the $\mathrm{OH}$ of solution with metal ions, cause the removal rate declined. After overall consideration, the optimal $\mathrm{pH}$ should be 7 . 


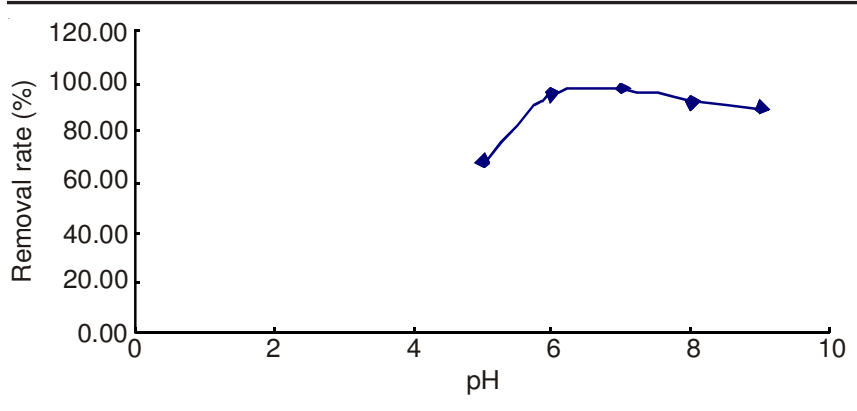

Fig. 4. Influence of $\mathrm{pH}$ on the treatment effect

Influence of the initial concentration of the wastewater to treatment effect: Taking $100 \mathrm{~mL} \mathrm{~Pb}^{2+}$ concentration is 5, $10,15,20,25$ and $30 \mathrm{mg} / \mathrm{L}$ of wastewater in six of the $250 \mathrm{~mL}$ beaker, respectively, adding the mass concentration of $20 \mathrm{~g} / \mathrm{L}$ of activated carbon, stirring $0.5 \mathrm{~h}$, analyzing supernatant, the results in Table-5 and Fig. 5.

\begin{tabular}{ccccccc}
\multicolumn{7}{c}{ TABLE-5 } \\
$\begin{array}{ccccccc}\text { INFLUENCE OF THE INITIAL CONCENTRATION } \\
\text { TO THE WASTEWATER REMOVAL RATE }\end{array}$ \\
$\begin{array}{c}\text { Initial conc. } \\
\text { wastewater (mg/L) }\end{array}$ & 5 & 10 & 15 & 20 & 25 & 30 \\
\hline $\begin{array}{c}\text { Removal rate of lead } \\
\text { ions (\%) }\end{array}$ & 97.8 & 98.6 & 90 & 83.2 & 82.3 & 79.0 \\
\hline
\end{tabular}

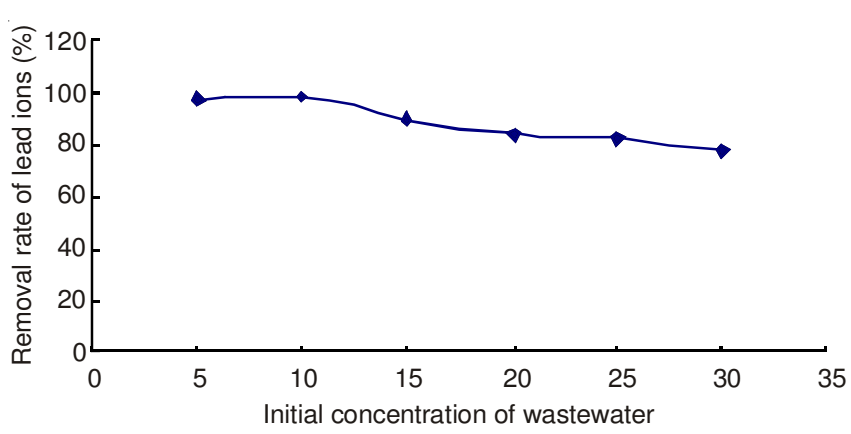

Fig. 5. Influence of initial concentration to the removal rate of lead ions
The experiment result shows that with the increase of concentration of $\mathrm{Pb}^{2+}$ in wastewater, the removal rate of $\mathrm{Pb}^{2+}$ has a downward trend, when the concentration of $10 \mathrm{mg} / \mathrm{L}$, the removal rate of $\mathrm{Pb}^{2+}$ maximum up to $98.6 \%$.

\section{Conclusion}

Activated carbon absorption efficiency of lead ions is affected by activated carbon dosage, mixing time, solution $\mathrm{pH}$ and of initial concentration of wastewater. The optimal concentration of activated carbon dosage is $20 \mathrm{~g} / \mathrm{L}$, the best stirring time is $0.5 \mathrm{~h}$, the optimum solution $\mathrm{pH}$ is 7 and when initial concentration of the wastewater is $10 \mathrm{mg} / \mathrm{L}$, activated carbon absorption efficiency is best. Only mastering these data fully, we can achieve better treatment effect in practical application.

\section{REFERENCES}

1. J.M. Xie, Chemical Industry of Jiangxi Province, 3, 35 (2010).

2. S.F. Zhang and X. Hu, Environ. Pollution Control Technol. Equip., 11, 68 (2003).

3. Green Energy Conservation and Environmental Protection Network, the Source of the Wastewater Containing Lead and Processing, vol. 4, p. 24 (2012).

4. The National Standard of the People's Republic of China, Integrated Wastewater Discharge Standard. 